\title{
Legal Aspects of Supply Ghain Continuity and Contingency Planning
}

\author{
Alan Gahtan
}

$\mathbf{T}$ here has been a lot of "good news" lately regarding the preparedness of many North American organizations to confront the Y2K menace. The current perception is that we will not likely see widespread and prolonged disruptions due to Year 2000 failures. However, it is likely that some disruptions will occur and hospitals need to take reasonable action to mitigate the impact and possible legal risks.

The supply chain survey, described by Baker and McGaw, will likely be useful to all hospitals for obtaining information regarding the Year 2000 readiness of their suppliers. However, any hospitals will likely continue to follow up with their more important suppliers (such as those of critical supplies, and those top $10-20 \%$ that supply the majority of the hospital's requirements). The survey results should also be helpful in assisting hospitals identify alternative suppliers in the event a disruption does occur.

Many organizations have now completed the awareness, inventory, remediation and testing phases of their Year 2000 program. The focus is now turning to clean management (to ensure the existing environment is not corrupted by the introduction of non-compliant products), supply chain continuity and contingency planning. These tasks, like the ones that preceded them, also have legal components.

With respect to clean management, the problem for many hospitals is that not all acquisitions are processed through a centralized purchasing function. In many cases, new products and services may be purchased directly by individual departments and staff members without formal purchase orders. In some cases, software or other minor acquisitions may even be charged by a staff member to their personal credit card. Equipment may also be brought in for evaluation during the period prior to a formal acquisition. Hospitals should ensure that any products and services acquired in this manner are also subject to policies and procedures enacted to protect the hospital from Year $\mathbf{2 0 0 0}$ risks. In fact, this is an issue which has implications beyond the Year 2000 problem and has prompted some organizations to initiate a general review of their purchasing function.

During the remainder of this year, hospitals should continue to ensure that new supply contracts, and those renewing prior to the year 2000 , contain appropriate legal terms relating to Year 2000. Simply pasting in a Year 2000 warranty, without a review of other terms and conditions is not sufficient. Other provisions, including force majeure (Act of God), remedies, and exclusions and limitations on liability, are also important. For instance, in the case of the force majeure provision, a customer would want to ensure that such a provision is narrow in scope, and that even in the event a cause beyond the reasonable control of the supplier materializes, the supplier is still obligated to use reasonable efforts to meet its obligations.

The objective is not to encourage hospitals to rely exclusively on the contract or to encourage litigation, but rather, to ensure that if a shortage does occur, the hospital will be the last to get cut off. Some organizations are even asking for terms which explicitly require the supplier to provide them with preference should a shortage occur. Less powerful customers should at least attempt to negotiate provisions which require the supplier to provide them with a pro-rata allocation of supply in the event of a shortage.

Hospitals should also avoid the opposite extreme. An attempt to make the supplier liable for all damages should a disruption occur, not withstanding the supplier's best efforts to address its supply chain issues, will not likely be accepted and will simply prolong the negotiation process.

Of course, regardless of the steps taken to enhance their legal position, hospitals should take appropriate steps to mitigate their supply chain risks.
When faced with a possible risk to the supply of required products, a reasonable and rational response is to increase inventory. However, while this approach may be successful for some organizations, it may lead to problems for the industry as a whole and may create artificial shortages, even before January 2000. Such shortages will encourage even greater hoarding, leading to even greater shortages. A self-fulfilling prophecy will therefore be realized to the detriment of everyone.

In terms of legal obligations, hospitals are expected to do what is reasonable in the circumstances. Hospitals are not expected to build up inventory in order to guard against very remote risks. An evaluation of what is likely to occur should therefore guide any decision to build up inventory.

Contingency planning activities should be conducted in consultation with a hospital's important suppliers. This activity can be expected to benefit the supplier as well as the hospital. The reduction in dependency on the supplier by the hospital will reduce the extent of any liability the supplier might otherwise incur to the hospital in the event the supplier does in fact experience a disruption.

In some cases, a supplier may be more than happy to increase their sales this year, particularly if given sufficient and timely notice. However, this will not always be the case. Some suppliers may be reluctant to increase their supply capacity to address a short term need if this would entail additional costs. For instance, the supplier of medical gases may not be unhappy to increase its sale of gases but may be reluctant to acquire additional cylinders if it expects demand to drop next year.

It is therefore important for hospitals to be aware that a particular supplier's interest may not be the same as the hospital's. Acknowledging this difference can make it easier to identify the real bottlenecks in the contingency planning and supply chain exercise. In some cases, it may be appropriate for the customer to at least partially contribute or compensate the supplier for additional costs it must incur in order to reduce the customer's risk.

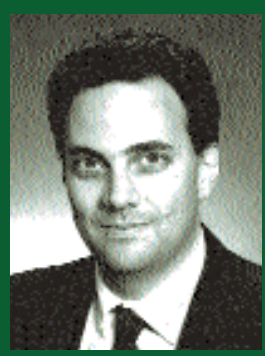

Alan Gahtan practices information technology law at Bennett Jones and is a member of their multidisciplinary Year 2000 practice group and their Health Law Group. Mr. Gahtan also maintains Websites on computer law, electronic commerce and Year 2000 legal issues at www.gahtan.com.

Alan Gahtan 